\title{
Mining technological homogeneity and its composition
}

\author{
Gennady Sekisov ${ }^{1 *}$ and Alexey Yakimov $^{2}$ \\ ${ }^{1}$ Mining Institute of the Far Eastern Branch of Russian Academy of Sciences, Khabarovsk, Russia \\ ${ }^{2}$ Transbaikal State University, Chita, Russia
}

\begin{abstract}
Annotation. It is proposed with the initial justification, as a new scientific and production category in the field of development of deposits of solid minerals, it is noted - "Mining technological homogeneity". At the same time, its high relevance, as well as the important role in the solution of the current problem of scientific and practical substantiation and in achieving a significant increase in the efficiency of the development of deposits of solid minerals, in the creation and rational use of innovative mining technologies. The system-complex composition of mining-technological mineral homogeneity as a subject conceptual-terminological category and, mainly, as a scientific and production activity associated with exploration, deposits of solid minerals is presented. The content of this category, as a scientific and industrial activity
\end{abstract}

\section{Introduction}

The trend of increasing with years of mining, obtaining and using various mineral products $[1,2]$ under modern conditions is accompanied in most cases and in many countries, including Russia with its Far Eastern region, by a significant decrease in the quality of the extracted and used both natural and man-made mineral raw materials [2,3]. In particular, over the last 25-30 years, the iron content in the ore has decreased almost 1.3 times [1.2], in the ores of precious metals, mainly gold - about 1.3-1.8 times [2].

This is due to a number of objective and subobject factors.

The decline in the quality of ores and some other minerals in demand is due to the following main reasons:

1. The development of so-called rich deposits and the involvement (in increasing quantities) in the development of mineral objects with a relatively low content of useful components. For example, man-made placers with a gold content of another $80 \mathrm{mgr}$, natural placers - with a gold content of up to 1-1.3 g / $\mathrm{t}$ are often worked out in a dredging way.

2. Forced development of deposits of difficult-enriching, so-called resistant ores.

3 . High heterogeneity of the material composition of natural and man-made both macroand mini mesomineral areas involved in development.

\footnotetext{
*Corresponding author: adm@igd.khv.ru
} 
4. Imperfection of widely used traditional technologies of mining operations, using of which a high dilution of the extracted mineral raw materials occurs, which often reaches $15-18 \%$ or more [4].

In these conditions, first of all, rational formation and allocation within the processed areas of the mineral deposit relatively homogeneous elements (mini and mesoexploitation blocks) as well as their subsequent separate (selective) excavation. Mineral homogeneity of such elements is proposed to be expressed terminologically by the category 'technological mineral uniformity. With reference to the mining sphere it is expedient to use the terminological category "Mining technological homogeneity".

\section{Scientific and practical justification}

It should be noted that the category "Technological mineralogy" [5], which, as, will be shown below, represents (in its own designation) as a very important component of the category "Mining technological homogeneity", If broadly understood as its specific scientific and production activity (Figure 1).

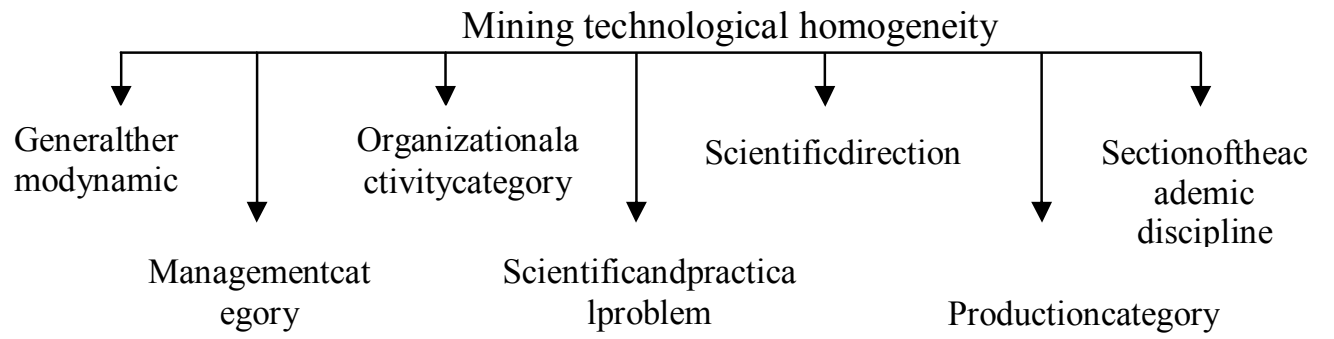

Fig. 1. The composition of the general category - "mining technological homogeneity" in the aspect of the main functionality of scientific-production and educational activities

In terms of overall aggregation, we propose the following categories of mineral uniformity of mining and geological objects: natural-gas-mineral; petromineral; selfmineral; likvamineralnaya, to which it is advisable to classify the mineral-mineral homogeneity and the brine-mineralogical homogeneity; building and pedigree; hydromineral and peat-mineral.

The categories of real-sectoral mineral uniformity are represented schematically in Fig. 2

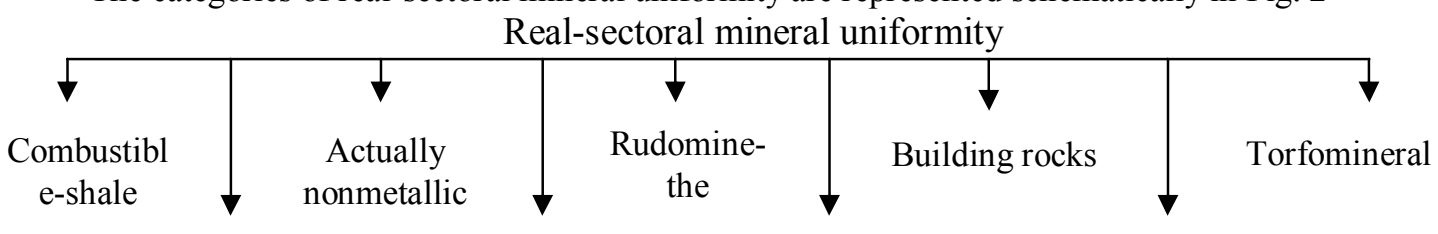
Carbon Mineral
Rhizospecomineral
Stone-mineral and mineral
General petro- mineral

Fig. 2. Categories of mineral uniformity, allocated in the general-sectoral aspect 
By origin of the original mineral objects of mineral uniformity, we distinguish the following general categories:

I. Mineral homogeneity of natural mineral objects.

II. Mineral homogeneity of technogenic mineral objects.

III. Mineral homogeneity of natural-technogenic mineral objects, to which, first of all, the previously abandoned springs, mineral panels, mineral bodies and their elements in the side parts of quarries, coal and slate sections belong, in particular.

The distinguished categories of mineral homogeneity for some other important features are represented by the schemes (Figure 3-5) and in textual reflection.

Nowadays, the production-stage mineral uniformity acquires great importance, the initial composition of which is schematically represented in Fig. 3.

Mineral homogeneity

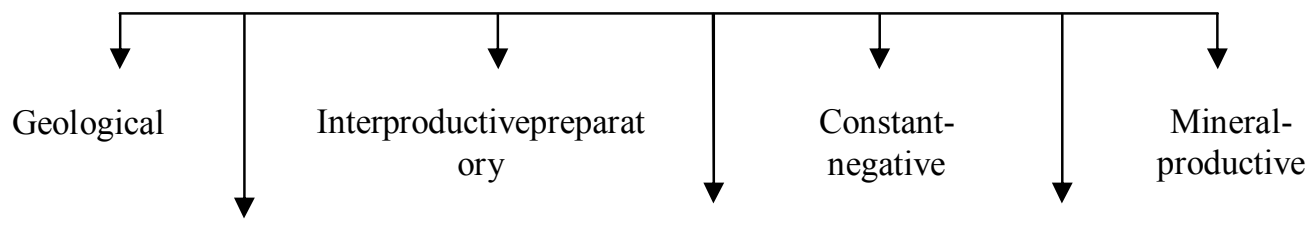

Operational

The actual primary processing, enrichment
Chemicalmetallurgical

Fig. 3. The initial composition of mineral uniformity in the aspect of the main categories of industrial mineral objects (MO)

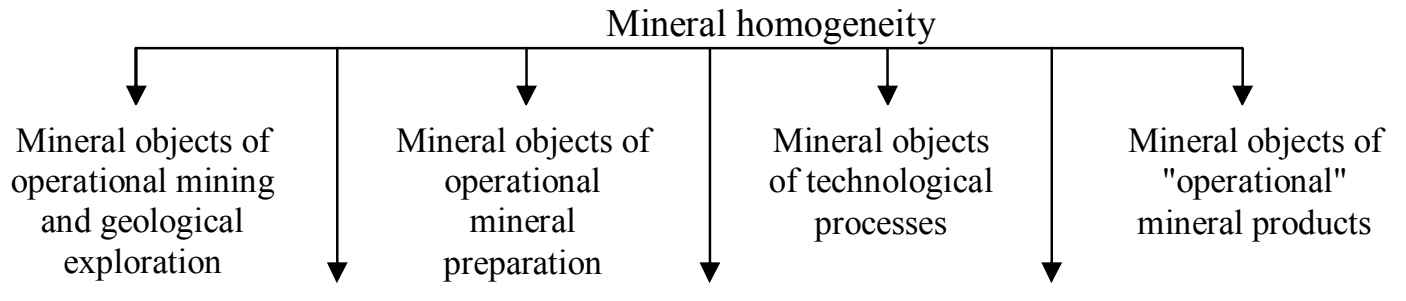

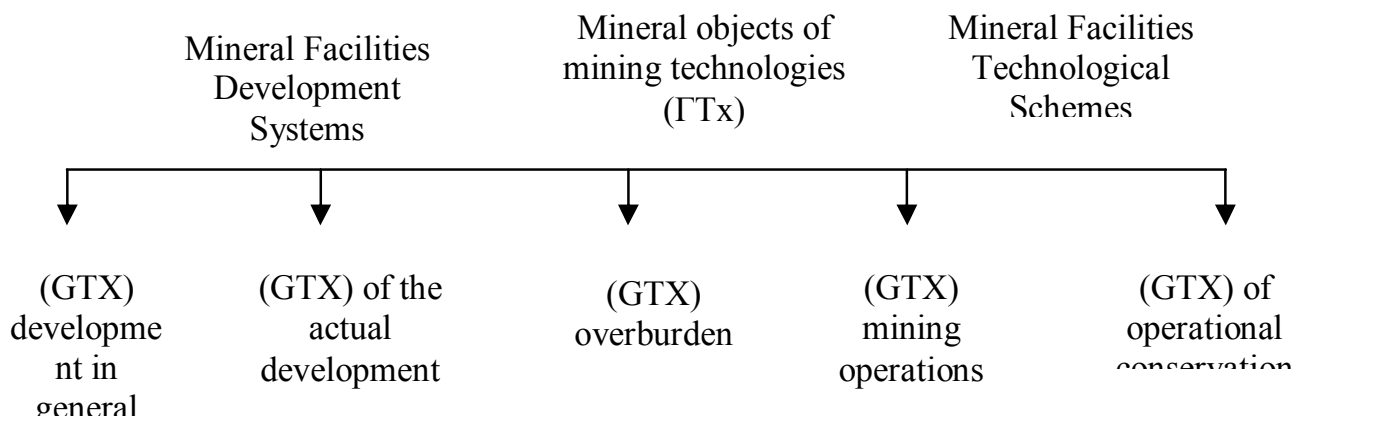

Fig.4. The initial composition of mineral uniformity in the aspect of mineral objects of production operational-technological staging

The distinguished main subcategories of mineral homogeneity in the aspect of spatial localization of mineral objects have a physico-geographical, strictly geological, geophysical, geochemical very complex spatial localization from the point of effective excavation of their MO; quantitative mineralogyogeneity; quantitative chemical-element homogeneity; quantitative mineral uniformity; quantitative complex-material mineral uniformity. 
Quantitative-qualitative mineral uniformity is a homogeneity characterized by modern qualities and quantitative features, i.e. manifestations of these features simultaneously in the relationship.

\section{Mineral homogeneity}

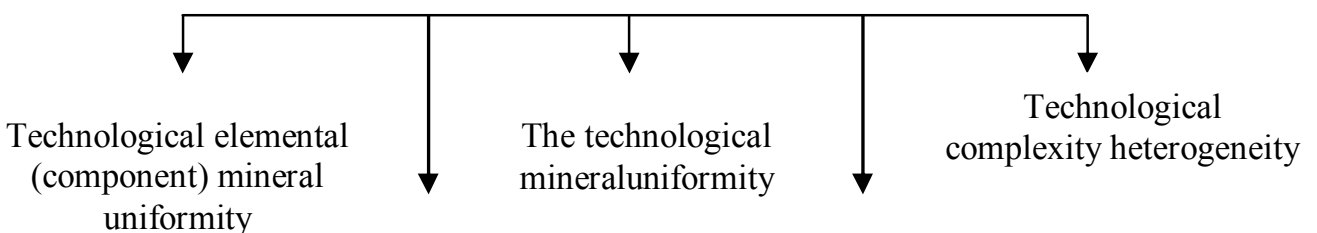

Technological mineralogy

Technological complex-material

mineral uniformity

Fig.5. The composition of mineral uniformity in terms of the basic properties of mineral-geochemical materiality

[Under the sub-term "miner-" is meant various possible minerals, especially hard minerals, in particular - ores, coal, etc.]

The uniformity of mineral objects of technological processes of development and development of deposits of solid minerals (especially ore minerals), including:

1. Operational geological exploration.

2. Destruction and loosening of rocks.

3. Reclamation and loading operations.

4. Explosive crushing of rock mass and oversize.

5. Operational mineral preparation.

6. Transportation of rock mass.

7. Warehousing and heaping.

8. Primary processing (mainly enrichment).

In terms of complex quantitative and qualitative features of mineral objects, the composition of mineral uniformity (in a brief reflection) is presented in the form of the following initial subcategories:

I. Qualitative mineral uniformity, in which the quality of gold-bearing ores is manifested in the following indicators [6,7]:

- level of gold content in mineral objects and formations;

- uneven distribution of gold in them;

- the fineness of gold particles and the difference in the shapes of gold;

- Mineral purity of gold and other quality indicators.

II. Quantitative mineral homogeneity, which is not so diverse in its manifestation and is reduced, mainly, to the following sub-categories of homogeneity: quantitative mineralogy ore of the main object-applied purpose: quantitative geochemical, qualitative geophysical. The composition from the standpoint of the general materiality of mineral uniformity in terms of its basic properties is as follows.

III. Quantitative-qualitative mineral uniformity is homogeneity. Characterized by combined qualities and quantitative features, i.e. manifestations of these features simultaneously in the relationship.

IV. General real-technological mineral uniformity.

V. Technological physico-mineral homogeneity, to which, mainly, homogeneity of the physical properties of mineral objects and formations, and in general - the geophysical properties of mineral objects and formations are relevant. 
VI.Technological chemical-mineral homogeneity, which includes geochemical homogeneity.

VII.Technologicalphysico-chemical-mineral homogeneity;

VIII.Technological mineral and technical homogeneity, i.e. uniformity of technical properties of mineral objects and formations.

\section{Results}

Mineral homogeneity is first introduced and initially justified as a new and highly relevant scientific and production category in the field of mining and the development of mineral objects in particular. The significant mineral heterogeneity of natural and natural-technical mineral objects, especially gold ore and noble metals in general, and, in particular, the relative mineral uniformity of the mineralized and excavated mineral objects of development and excavation within natural and technogenic mineral formations are noted and disclosed.

On the basis of the system complex of important aspects (features), the composition of mineral homogeneity is established as the basic subject aggregate of categories.

In particular, technological mineral uniformity, material, economic, energy and a number of other categories are represented.

At the same time, mineral uniformity in a wide range is presented as a scientific and production activity.

\section{Conclusions}

The main conclusions include the following:

Mineral homogeneity is one of the most important categories of scientific and industrial activity in the field of mining-geological and economically efficient development of mineral formations and objects and the use of mineral resources in general.

The results of activities in the field of achieving mineral uniformity and its realization, especially - mineralogical - homogeneity, acquire great importance in modern conditions, primarily from the standpoint of providing a number of positive consequences. Particularly important is its role in implementation: a significant reduction in the energy intensity of technological processes and the development of deposits in general; reduction of capital and operating costs; increase in labor productivity; reduction of socio-economic costs of mineral industries; increase the completeness of excavation and use of minerals and mineral resources and subsoil as a whole; improving the quality of mineral raw materials and mineral products derived from it; raising the culture of work and various mineral industries.

The composition and structure of mineral uniformity of mining technology objects and technological schemes are established in a hierarchical sequence and volumetric (using the systemic complex of basic features). Subject to the use of systemic mineral uniformity of mineral objects, it is possible to rationalize traditional and create innovative mining technologies for developing deposits and mining and metallurgical and chemicalmetallurgical technologies for the production of mineral products and metals.

\section{References}

1. Grovson P.C.F. Miberals handbook 2000-01 Stanstic analyses of the woreds minerals indystry / Endinbridge. Mining jornal books. (2001). 
2. Arkhipov GI Mineral Resources of the Mining Industry of the Far East. Overview of the state and development opportunities. "The Mountain Book.".830p. (Mining book - Far East). (2011).

3. Van-Van-E A.P. Resource base of natural-technogenic gold deposits. "The Mountain Book." Publishing house MGGU. 268 pp. (Mining book - Far East). (2010).

4. Sekisov GV, Zykov NV Mastering mineral objects and evaluation methodology. Moscow: Publishing House "Mining Book". P.295-311. (2012).

5. Mountain Science. Development and reduction of the Earth's interior. / Ed. K.N. Trubetskoy. Publishing House of the Academy of Mining Sciences. P. 392-394. (1997).

6. Bushmin S. A., Belyavsky B. V., Glehovskiy V. A., Borko A. K. ISOCHRON RFOS AGE of gold from the Magskoe gold-Quartz vein dein deposit (Northern Karelia, Baltic Sheld). DokladyEarthSeiences. 448 (1). P. 54-57. (2013).

7. Sekisov GV, Sobolev AA, Nigay EV. Mining information-analytical bulletin. 2. P. 192-201. (2011). 